\title{
Care management dalam pendidikan
}

\author{
Adhe Kusuma Pertiwi *, Nurul Ulfatin, Ahmad Yusuf Sobri \\ Universitas Negeri Malang. \\ Jl. Cakrawala No. 5, Sumbersari, Lowokwaru, Malang, Jawa Timur 65145, Indonesia. \\ * Corresponding Author. Email: adhe4555@gmail.com
}

\section{ARTICLE INFO \\ Article History \\ Received: \\ 9 July 2020; \\ Revised: \\ 25 September 2020; \\ Accepted: \\ 25 September 2020 \\ Available online: \\ 25 September 2020}

\section{Keywords}

Pasangan muda; Persoalan peserta didik;

Manajemen layanan

khusus;

Care management;

Special service

management;

Students;

Young parents

\begin{abstract}
Perhatian terhadap persoalan yang dihadapi peserta didik sekolah dasar dengan orang tua tergolong pasangan muda masih rendah. Perlu adanya layanan khusus untuk menyikapi persoalan ini, mengingat peserta didik pada usia sekolah dasar masih dalam proses pembentukan karakter. Layanan care management merupakan layanan khusus dimana terjadi kolaborasi dan integrasi yang kompleks sehingga sesuai untuk mengatasi persoalan ini. Tujuan penelitian ini untuk mengetahui persoalan dan pemicu peserta didik dengan orang tua tergolong pasangan muda serta layanan care management yang diberikan oleh SD Negeri Lowokwaru 3 Malang dan SD Negeri Lowokwari 4 Malang dalam mengatasi persoalan tersebut. Metode yang digunakan dalam penelitian ialah kualitatif dengan jenis penelitian multisitus. Teknik pengumpulan data dilakukan melalui wawancara, obervasi, dan dokumentasi. Hasil penelitian menunjukkan jika pemicu persoalan disebabkan oleh keadaan pendidikan, ekonomi, dan emosi dari orang tua tergolong pasangan muda. Adanya pemicu ini menyebabkan adanya perkembangan yang berbeda dari peserta didik dilihat dari segi fisik, emosi, sosial, dan intelektual. Mengatasi persoalan ini sekolah menerapkan layanan care management dengan mempertimbangkan edukasi, care coordination, transition management, compliance, dan utilization management.
\end{abstract}

The care of problems that happen to elementary school students with parents classified as young couples is still low. It is necessary to have a special service to broadcast this topic, considering that students in the early stages of school are still in the process of character building. Maintenance management services are specialized services where complex collaboration and integration occur in order to overcome this problem. The purpose of this study is to study the discussion and triggers of students with parents belonging to young couples and management services provided by SDN Lowokwaru 3 Malang and SDN Lowokwari 4 Malang in an effort to overcome these problems. The method used in this study is qualitative with a type of multi-site research. Data collection techniques carried out through interviews, observation, and documentation. The results showed that there were triggers from education, economy, and transition from parents who were classified as young couples. The existence of these triggers causes a different development of students in terms of physical, emotional, social, and intellectual. Care Management, with consideration of education, care coordination, transition management, compliance, and utilization management.

This is an open access article under the CC-BY-SA license.

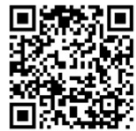

How to cite:

Pertiwi, A. K., Ulfatin, N., \& Sobri, A. Y. (2020). Care management dalam pendidikan. Jurnal Akuntabilitas Manajemen Pendidikan, 8(2), 205-215. doi: https://doi.org/10.21831/jamp.v8i1.33160 


\section{PENDAHULUAN}

Pendidikan menjadi urgensi kehidupan dimasa modern seperti saat ini. Semakin tinggi tingkat pendidikan semakin tinggi pula kualitas hidup yang ditandai dengan peningkatan seluruh aspek emosi, sosial, dan fisik dalam kehidupan individu (World Health Organization, 2010). Pendidikan di Indonesia terbagi pendidikan menjadi tiga jenis, yakni pendidikan formal, pendidikan non formal, dan pendidikan informal (Purnamasari, 2017). Pendidikan informal atau keluarga memegang andil dalam keberhasilan pendidikan formal. Pendidikan keluarga memiliki pengaruh besar dalam kehidupan anak karena keluarga merupakan basis pendidikan pertama, terpenting, dan terdekat yang didapat oleh anak, sehingga penumbuhan dan pengembangan moral yang ada dalam diri anak yang memungkinkan mencapai ketahanan moral, dapat dioptimalisasikan melalui kerangka asih, asah, dan asuh yang mengakar pada tiga potensi yakni rasa, cipta, dan karsa pendidikan (Suardi, 2016).

Keluarga berperan dalam proses pemberian nilai-nilai positif bagi tumbuh kembang anak sebagai fondasi pendidikan selanjutnya (Mansur, 2005). Penelitian yang dilakukan oleh (Kharmina, 2011) menyatakan jika pola asuh orang tua dengan latar belakang pendidikan yang memadai menghasilkan pola asuh yang memadai karena terdorong untuk meningkatkan kualitas pola asuh anak agar tejadi satu keutuhan serta keharmonisan kerja di sekolah, sehingga proses dan output pendidikan bisa maksimal. Hasil uji pengaruh yang dilakukan (Setyowati, Krisnatuti, \& Hastuti, 2017) menunjukkan bahwa tingkat pendidikan ayah dan ibu berpengaruh positif terhadap kesiapan menjadi orang tua. Penelitian ini didukung oleh penelitian yang dilakukan oleh (Ghalili, Etemadi, Ahmadi, Fatehizadeh, \& Abedi, 2012), yang menyatakan jika semakin tinggi umur dan tingkat pendidikan orang tua, maka kesiapan menikahnya semakin baik. Pentingnya mempersiapkan finansial dan moral atau emosi berhubungan dengan kematangan emosi dan usia ibu saat memiliki anak (Brisbane, 2010). Selain itu, status ekonomi juga memegang peranan penting. Atika dan Rasyid (2018) menyatakan bahwa jika anak yang berasal dari keluarga dengan status sosial ekonomi tinggi, maka anak tersebut akan memiliki keterampilan sosial yang jauh lebih baik jika dibandingkan dengan anak yang berasal dari keluarga dengan status sosial ekonomi yang rendah.

Sekolah dasar menjadi tahap awal anak mendapatkan pendidikan setelah sebelumnya telah mendapatkan latihan pada jenjang pra sekolah. Usia 7-12 tahun dengan perkembangan mentalintelektual anak yang berada pada tahap konkret operasional. Konkret disini anak hanya mampu memahami hal yang berbentuk dan operasional karena mulai berfikir dengan cara sistematis dan logis (Piaget \& Barbel, 2010). Keterampilan yang dicapai oleh anak sekolah dasar yakni social-help skills dan play skill. Social-help skills ialah keterampilan dalam membantu orang lain sedangkan, play skill terkait dengan kemampuan motorik seperti melempar, menangkap, berlari, dan keseimbangan. Selain itu pada kelas atas di usia sekolah dasar ini atau akhir masa kanak-kanak disebut dengan gang age (Kusmaedi, Husdarta, \& Hidayat, 2004) dimana anak berubah dari self centered, egoistis, senang bertengkar menjadi anak yang kooperatif, dan pandai menyesuaikan diri dengan kelompok. Mereka membuat kelompok dikarenakan dua atau tiga teman tidak cukup. Anak ingin bersama dengan kelompoknya, sebab dengan demikian terdapat cukup teman untuk bermain dengan jenis-jenis permainan yang dia gemari atau melakukan aktivitas lainnya untuk mendapatkan kegembiraan (Kusmaedi, Husdarta, \& Hidayat, 2004).

Adanya gang age pada anak sekolah dasar seringkali menimbulkan pergesekan, sekolah harus tanggap, dimana sebagian orang tua dengan umur dan latar pendidikan yang memadai menganggap olok mengolok atau konflik anak sekolah dasar sebagai masalah yang biasa terjadi, karena mereka masih tahap penyesuaian apalagi jika mereka masih berada di kelas rendah yakni kelas 1, 2, dan 3 . Akan tetapi, tidak bagi sebagian orang tua, terlebih jika orang tua tersebut merupakan pasangan muda yang baru saja memiliki anak. Mereka akan sensitif jika putra-putrinya terusik oleh anak lain terutama bagi seorang ibu. Menurut penelitian yang dilakukan oleh Black, Fernandez-Rao, Hurley, Tilton, Balakrishna, Harding, Reinhart, ... Nair (2016) menyatakan bahwa seorang ibu muda memiliki emosi yang tinggi ketika melahirkan anak pertama. Seorang Ibu yang menikah dalam usia muda akan kurang mampu memberikan pengasuhan yang baik. Ibu yang mempersiapkan dirinya untuk menjadi orangtua ditentukan oleh kesiapan sosial, finansial, dan pengalaman yang baik dalam mengurus anak (Biktagirova \& Valeeval, 2015). Muncul berbagai alasan, kenapa seorang pasangan 
memutuskan untuk menikah muda di masyarakat marginal Bangladesh memperlihatkan jika perempuan dan laki-laki memilih untuk segera menikah karena tingkat pendidikan ibu yang rendah.

Penelitian tentang pasangan usia muda yang menikah telah banyak dilakukan di berbagai negara baik menggunakan metode kualitatif maupun dengan menggunakan metode kuantitatif. Akan tetapi, penelitian yang selama ini dilakukan lebih berfokus pada kehidupan kelurga di rumah, yakni bagaimana pasangan muda menjalani kehidupan rumah tangga dan mengasuh anak di rumah. Hal tersebut dapat dijumpai pada penelitian sebelumnya pada tahun 2016, tentang Problema kehidupan berkeluarga pasangan suami istri kawin muda yang dilakukan oleh Lestari, Hanum, dan Nopianti (2016) dengan menggunakan pendekatan kualitatif. Penelitian tersebut menunjukkan jika masalah seperti latar belakang ekonomi, dilihat dari pengahasilan suami yang kurang memenuhi kebutuhan sehari-hari akan menyebabkan pasangan muda cenderung meminta bantuan kepada orangtua. Selain itu, peran suami dan istri dalam menjadi orang tua untuk pengasuhan anak pertama masih bergantung kepada orangtua. Penelitian tersebut belum sampai kepada tahap kehidupan anak dengan orang tua pasangan muda dalam menjalani proses belajar dan bersosialisasi di sekolah. Dalam penelitian ini menjelaskan lebih jauh tentang kehidupan peserta didik dengan orang tua pasangan muda dalam menjalani proses belajar di sekolah serta layanan khusus kepada peserta didik dengan latar belakang orang tua yang tergolong dalam pasangan muda, ekonomi, dan kondisi emosional orang tua.

\section{METODE}

Jenis penelitian yang digunakan dalam penelitian ini ialah penelitian multisitus. rancangan penelitian kualitatif yang melibatkan beberapa situs yang subjeknya diasumsikan memiliki karakteristik yang sama dan untuk mengembangkan teori yang diangkat dari latar serupa (Ulfatin, 2015, p. 70). Peneliti memilih lokasi penelitian di SD Negeri Lowokwaru 3 Malang yang beralamat di Jl. Sarangan No. 1, Lowokwaru, Malang, Jawa Timur dan SD Negeri Lowokwaru 4 Malang yang beralamat di Jl. Setaman No. 2, Lowokwaru, Malang, Jawa Timur. Peneliti merupakan instrumen kunci yang merencanakan, melaksanakan, mengumpulkan data, dan membuat laporan dalam suatu penelitian. Pernyataan tersebut didukung oleh pendapat Bungin (2011) yang menyatakan bahwa peran peneliti di lapangan merupakan kunci keberhasilan dari penelitian, sehingga dibutuhkan penghayatan secara total dari peneliti, seperti aktif berperan tempat penelitian melalui kegiatan wawancara, observasi, dan dokumentasi. Peneliti aktif hadir dalam kedua sekolah tersebut untuk mengambil data.

Sumber data penelitian ini adalah kepala sekolah, guru, orang tua, dan peserta didik dari kedua sekolah. Teknik pengumpulan data yang digunakan dalam penelitian ini adalah wawancara, observasi, dan dokumentasi. Pengecekan keabsahan dilakukan untuk menghindari kesalahan data yang akan di analisis, dalam pengecekan keabsahan data peneliti menggunakan triangulasi, pengecekan anggota, perpanjangan waktu pengamatan, dan kecukupan bahan referensi. Analisis data adalah proses menyusun data agar bisa ditafsirkan dan disimpulkan. Miles dan Huberman (dalam Ulfatin, 2015) menyebutkan bahwa prosesanalisis data meliputi pengumpulan data, reduksi data, penyajian data, dan verifikasi data. Tahapan penelitian meliputi tahap pendahuluan, yaitu peneliti melakukan observasi di SD Negeri Lowokwaru 3 Malang dan SD Negeri Lowokwaru 4 Malang. Observasi bertujuan agar peneliti mengetahui gambaran umum tentang lembaga, setelah itu peneliti menemukan hal yang menarik dan unik dari lembaga yang dijadikan fokus penelitian. Tahap penyusunan proposal bertujuan untuk memberikan gambaran secara umum tentang subyek penelitian dari hasil studi pendahuluan. Peneliti merancang proposal penelitian sebagai pedoman pelaksanaan penelitian guna mendapatkan hasil yang berkualitas. Tahap pelaksanaan dilakukan dengan menjaring data dan bukti dengan menggunakan metode yang dapat dipertanggungjawabkan secara ilmiah. Tahap penyusunan laporan dengan membuat laporan hasil penelitian yang dibuat secara deskriptif, naratif, obyektif, dan sistematis. 


\section{HASIL DAN PEMBAHASAN}

Hasil

Persoalan yang Dihadapi Peserta Didik Beserta Pemicunya dengan Orang Tua Tergolong Pasangan Muda

Pemicu persoalan peserta didik dengan orang tua pasangan muda di SD Negeri Lowokwaru 3 Malang dan SD Negeri Lowokwaru 4 Malang didominasi oleh tingkat pendidikan, ekonomi, dan ego dari masing-masing orang tua. Pemicu tersebut membawa dampak pada perkembangan peserta didik secara fisik, emosi, sosial, dan intelektual. Berdasarkan data yang diperoleh dari kedua sekolah diketahui bahwa orang tua yang tergolong dalam pasangan muda dengan tingkat pendidikan yang cukup, ekonomi yang matang, dan emosi yang stabil akan membawa dampak positif bagi anak, yakni secara fisik penampilan anak lebih bersih dan rapi, emosi anak lebih stabil, serta intelektual anak dapat lebih berkembang, karena perhatian yang cukup dari orang tua. Akan tetapi, orang tua dengan tipe ini cenderung overprotective, sehingga secara sosial anak sulit untuk berbagi dengan teman. Sedangkan untuk orang tua tergolong pasangan muda dengan tingkat pendidikan yang kurang, ekonomi kurang, dan emosi yang kurang stabil, maka orang tua dengan tingkatan seperti ini akan acuh terhadap anak. Hal ini mengakibatkan perkembangan peserta didik secara fisik kurang bersih dan rapi, perkembangan secara emosi sulit dikendalikan, intelektual anak rata-rata kurang, karena perhatian orang tua yang terbatas. Akan tetapi anak dengan latar belakang seperti ini lebih mudah bergaul dalam lingkungan sosial.

\section{Penanganan Persoalan Peserta Didik dengan Orang Tua Tergolong Pasangan Muda melalui Care Management}

Mengatasi persoalan orang tua yang tergolong dalam pasangan muda kedua sekolah, baik di SD Negeri Lowokwaru 3 Malang dan SD Negeri Lowokwaru 4 Malang menggunakan layanan care management dengan memperhatikan lima ruang lingkup dasar, yakni edukasi, care coordination, compliance, transition management, dan utilization management. Pertama, edukasi dilakukan untuk memberikan pemahaman kepada orang tua jika anak memiliki persoalan di sekolah. Guru akan menghubungi orang tua melalui chat pribadi untuk meminta bertemu langsung untuk menghindari kesalahpahaman dalam berkomunikasi. Kedua, care coordination dilakukan melalui pendataan identifikasi awal peserta didik berdasarkan wawancara, karena tes psikologi tidak dilakukan. Selain itu, untuk melihat persoalan yang terjadi berdasarkan pelanggaran tata tertib yang dilakukan. Selanjutnya, guru melakukan pendekatan ke orang tua dan peserta didik.

Ketiga, compliance dilakukan dengan mempertimbangkan kebijakan dari pemerintah dimana guru sekolah dasar harus lulusan S1 Pendidikan Guru Sekolah Dasar (PGSD) yang dibekali dengan kemampuan konseling untuk mengatasi persoalan peserta didik (Kementerian Pendidikan dan Kebudayaan Republik Indonesia, 2016). Keempat, transition management dilakukan melalui rapat pleno kenaikan kelas oleh guru dengan memberikan catatan peserta didik yang mengalami persoalan sebelumnya. Kelima, utilization management melalui penggunaan sumber daya dimiliki secara maksimal dalam penanganan persoalan peserta didik dengan orang tua tergolong pasangan muda, yakni dengan memberdayakan peserta didik, orang tua, guru, dan kepala sekolah.

Pembahasan

Persoalan yang Dihadapi Peserta Didik Beserta Pemicunya dengan Orang Tua Tergolong Pasangan Muda

Pasangan muda menghadapi tantangan untuk memperoleh keterampilan, pendidikan, dan pengalaman untuk mendapatkan pekerjaan yang baik dan mempertahankan keluarga (Sick, Spaulding, \& Park, 2018). Memiliki anak-anak di masa remaja dan dewasa dapat memengaruhi perkembangan identitas dengan penyesuaian masalah yang akan berdampak negatif pada hubungan pengasuhan anak (Afifi, 2007). Dampak negatif dari pengasuhan akan terbawa kepada anak sampai ia memasuki usia sekolah. Sekolah sebagai tempat anak mendapatkan pendidikan baik secara akademis maupun sosial harus peka pada persoalan ini. 
Penelitian di SD Negeri Lowokwaru 3 Malang dan SD Negeri Lowokwaru 4 Malang menjelaskan bahwa peserta didik dengan orang tua yang tergolong pasangan muda sering terlibat persoalan yang didominasi persoalan pada tingkat pendidikan, ekonomi, dan ego dari masing-masing orang tua. Status sosial ekonomi seseorang memiliki peranan terhadap perkembangan putra-putrinya. Sugihartono (2015) menyatakan bahwa status sosial ekonomi orang tua meliputi tingkat pendidikan orang tua, pekerjaan, dan penghasilan orang tua. Dimana tinggi rendahnya status tersebut mempengaruhi emosi pasangan muda. (Lestari, Hanum, \& Nopianti) menambahkan problema kematangan emosi berdampak pada keseharian suami dan istri dalam mengatasi masalah rumah tangga cenderung saling mempertahankan ego masing-masing.

Keluarga dengan status sosial ekonomi yang baik akan memberikan perhatian baik pula dalam pemenuhan kebutuhan sehari-hari, serta akan memikirkan masa depan putra-putrinya (Chotimah, Ani, \& Widodo, 2017). Sugihartono (2015) menyatakan bahwa status sosial ekonomi orang tua meliputi tingkat pendidikan orang tua, pekerjaan orang tua, dan penghasilan orang tua. Selain itu, Lestari, Hanum, dan Nopianti (2016) menyatakan bahwa problema kematangan emosi berdampak pada keseharian suami dan istri dalam mengatasi masalah rumah tangga yaitu cenderung saling mempertahankan egonya masing-masing. Penelitian yang dilakukan oleh Erola, Jalonen, dan Lehti (2016) menyebutkan bahwa status sosial orang tua yang menyangkut tingkat ekonomi dan pendidikan akan mempengaruhi keberlangsungan hidup anak ke depannya.

Latar belakang keluarga yang berbeda-beda dari setiap peserta didik mengakibatkan perkembangan mereka secara fisik, emosi, sosial, dan intelektual akan berbeda pula antara satu dengan yang lainnya. Orang tua yang tergolong dalam pasangan muda dengan tingkat pendidikan yang cukup, ekonomi yang matang, dan emosi yang stabil, akan membawa dampak positif bagi anak yakni secara fisik penampilan anak lebih bersih dan rapi, emosi anak lebih stabil, serta intelektual anak lebih berkembang, karena perhatian yang cukup dari orang tua. Akan tetapi, orang tua dengan tipe ini cenderung overprotective, sehingga secara sosial anak akan sulit untuk berbagi dengan teman. Sedangkan untuk orang tua yang tergolong dalam pasangan muda dengan tingkat pendidikan yang kurang, ekonomi kurang, dan cenderung memiliki emosi yang kurang stabil, maka orang tua dengan golongan seperti ini akan cenderung acuh terhadap anak. Hal ini mengakibatkan perkembangan peserta didik secara fisik kurang bersih dan rapi, perkembangan secara emosi sulit dikendalikan, intelektual anak rata-rata kurang karena perhatian orang tua yang terbatas. Akan tetapi anak dengan latar belakang seperti ini memilliki sosial yang lebih mudah bergaul dengan lingkungan sosial.

Penanganan Persoalan Peserta Didik dengan Orang Tua Tergolong Pasangan Muda melalui Care Management

Care management adalah cara yang digunakan untuk mewujudkan hak peserta didik untuk menentukan pilihan pelayanan sesuai dengan kebutuhan dan harapan (Morales-Asencio, MartinSantos, Morilla-Herrera, Fernández-Gallego, Celdrán-Mañas, Navarro-Moya ... Carrasco, A. M., 2010). Terdapat 5 ruang lingkup layanan care management di SD Negeri Lowokwaru 3 Malang dan SD Negeri Lowokwaru 4 Malang, yaitu: edukasi, care coordination, compliance, transition management, dan utilization management. Lingkup pertama pada layanan care management di SD Negeri 3 Malang dan SD Negeri Lowokwaru 4 Malang adalah edukasi. Edukasi dalam hal ini dilakukan dengan komunikasi antara guru dan orang tua melalui chat pribadi untuk meminta bertemu langsung dalam menghindari kesalahpahaman pada saat berkomunikasi. Komunikasi antara guru dan sekolah penting dilakukan karena dengan adanya komunikasi yang baik akan meningkatkan kualitas belajar peserta didik, sebaliknya apabila komunikasi buruk maka kualitas belajar akan menurun (Megawati \& Kahar, 2015). Partisipasi orang tua atau wali dalam bentuk ide, kritik, dan dukungan konstruktif dalam pelaksanaan pendidikan akan dapat mengantarkan peserta didik mencapai tujuan dan pembentukan kepribadian, sehingga membangun komunikasi yang intensif, proaktif, professional, dan agar tidak terjadi kesalahpahaman (Subiyanto, 2011).

Care coordination dilakukan dengan cara pendekatan guru ke orang tua dan peserta didik, dengan tetap berpedoman pada tata tertib sekolah. Menurut Irwansa dan Maf'ul, 2015) pelaksanaan tata tertib sekolah dijadikan sebagai alat kontrol terhadap peserta didik. Selain itu, guru perlu mengenal baik tiap karakteristik peserta didiknya dengan mengenal minat dan bakat-bakat khusus para peserta didik untuk memberikan pengalaman pendidikan yang dibutuhkan oleh masing-masing 
peserta didik ketika mengembangkan bakat mereka secara optimal sesuai dengan tujuan pendidikan (Abdullah, 2017). Selain pendekatan ke peserta didik, guru juga perlu melakukan pendekatan ke orang tua murid. Hal ini berguna dalam membangun prestasi peserta didik, karena keterlibatan orang tua dan guru dalam menunjang ketercapaian prestasi peserta didik adalah indikator utama bagi kesuksesan sekolah (Comce, Muniarti, \& Nasir, 2017).

Compliance berkaitan dengan penanganan persoalan peserta didik dengan orang tua yang tergolong dalam pasangan muda yang dilakukan oleh guru dengan pertimbangan bahwa guru memiliki kualifikasi kemampuan dalam memberikan layanan konseling. Seperti yang disebutkan dalam Peraturan Menteri Pendidikan Nasional Nomor 16 Tahun 2007 tentang Standar Kualifikasi Akademik dan Kompetensi Guru. Bimbingan dan konseling di sekolah dasar menurut Nurihsan dan Sudianto (2005) perlu dilakukan oleh guru sebagai upaya dalam pemberian bantuan kepada peserta didik yang dilaksanakan secara berkesinambungan. Lingkup transition management dilakukan melalui rapat pleno kenaikan kelas oleh guru dengan memberikan catatan-catatan kepada peserta didik yang mengalami persoalan. Dalam rapat ini akan dibahas khusus mengenai kenaikan kelas. Pengertian kenaikan kelas adalah peserta didik yang telah dapat menyelesaikan program pendidikan, jika telah memenuhi persyaratan untuk dinaikkan, maka kepadanya berhak untuk naik kelas berikutnya (Amirin, 2013). Selain itu, mutasi peserta didik dilakukan melalui kenaikan kelas, peserta didik pindahan, dan kelulusan peserta didik.

Kedua sekolah baik di SD Negeri Lowokwaru 3 Malang dan SD Negeri Lowokwaru 4 Malang melaksanakan lingkup utilitaztion management melalui pemaksimalan penggunaan sumber daya yang dimiliki dalam penanganan persoalan peserta didik dengan orang tua yang tergolong pasangan muda. Utilitaztion management dilakukan dengan cara memberdayakan peserta didik, orang tua, guru, dan kepala sekolah. Elemen pada sistem sekolah antara lain adalah peserta didik, kepala sekolah, pendidik atau guru, staf tata usaha, kurikulum, dan fasilitas pendidikan lainnya (Departemen Pendidikan Nasional, 2006).

\section{SIMPULAN}

Persoalan tentang peserta didik dengan orang tua yang tergolong dalam pasangan muda telah banyak terjadi di sekolah, sehingga mempengaruhi karakteristik peserta didik. Pemicu persoalan peserta didik dengan orang tua yang tergolong pasangan muda di SD Negeri Lowokwaru 3 Malang dan SD Negeri Lowokwaru 4 Malang didominasi oleh tingkat pendidikan, ekonomi, dan ego dari masing-masing orang tua. Pemicu tersebut membawa dampak pada perkembangan peserta didik baik secara fisik, emosi, sosial, dan intelektual. Penanganan persoalan peserta didik dengan orang tua pasangan muda dilakukan melalui layanan khusus care management, dimana terdapat 5 aspek layanan yakni edukasi, care coordination, compliance, transition management, dan utilization management. Pertama, edukasi yaitu memberikan pemahaman kepada orang tua jika anak memiliki persoalan di sekolah. Guru akan menghubungi orang tua melalui chat pribadi untuk meminta bertemu langsung untuk menghindari kesalahpahaman dalam berkomunikasi. Kedua, care coordination yaitu identifikasi awal peserta didik berdasarkan wawancara. Ketiga, compliance dimana guru dalam menangani persoalan harus memiliki kualifikasi sesusai kebijakan pemerintah. Keempat, transition management yang dilakukan dengan cara rapat pleno kenaikan kelas oleh guru dengan memberikan catatan peserta didik yang mengalami persoalan sebelumnya. Kelima, utilization management yaitu pemaksimalan penggunaan sumber daya dimiliki dalam penanganan persoalan peserta didik.

\section{DAFTAR PUSTAKA}

Abdullah, A. (2017). Pendekatan dan model pembelajaran yang mengaktifkan siswa. EduReligia: Jurnal Pendidikan Agama Islam, 1(1), 45-62. doi: https://doi.org/10.33650/edureligia.v1i2.45

Afifi, T. O. (2007). Child abuse and adolescent parenting: Developing a theoretical model from an ecological perspective. Journal of Aggression, Maltreatment, \& Trauma, 14(3), 89-105. doi: https://doi.org/10.1300/J146v14n03_06 
Amirin, T. (2013). Manajemen pendidikan. Yogyakarta: UNY Press.

Atika, A. N., \& Rasyid, H. (2018). Dampak status sosial ekonomi orang tua terhadap keterampilan sosial anak. PEDAGOGIA: Jurnal Pendidikan, 7(2), 111-120. doi: https://doi.org/10.21070/pedagogia.v7i2.1601

Biktagirvoa, G. F., \& Valeeva, R. A. (2015). Formation of university students' readiness for parenthood. Review of European Studies, 7(4), 93-97. doi: https://dx.doi.org/10.5539/res.v7n4p93

Black, M. M., Fernandez-Rao, S., Hurley, K. M., Tilton, N., Balakrishna, N., Harding, K. B., Reinhart, G., Radhakrishna, K. V., \& Nair, K. M. (2016). Growth and development among infants and preschoolers in rural India: Economic inequities and caregiver protective/promotive factors. International Journal of Behavioral Development, 40(6), 526535. doi: https://doi.org/10.1177/0165025416644690

Brisbane, E. H. (2010). The developing child ( $2^{\text {nd }}$ ed.). McGraw-Hill Education.

Bungin, B. (2011). Metodologi penelitian kualitatif: Aktualisasi metodologis ke arah ragam varian kontemporer. Jakarta: PT Raja Grafindo Persada.

Chotimah, L. N., Ani, H. M., \& Widodo, J. (2017). Pengaruh status sosial ekonomi orang tua terhadap prestasi belajar siswa (Studi kasus siswa kelas VIII SMP Negeri 1 Jember tahun ajaran 2016/2017). Jurnal Pendidikan Ekonomi: Jurnal Ilmiah Ilmu Pendidikan, Ilmu Ekonomi dan Ilmu Sosial, 11(1), 75-80. doi: https://doi.org/10.19184/jpe.v11i1.5004

Comce, H., Murniati, A. R., \& Usman, N. (2017). Komunikasi wali kelas dengan orang tua siswa dalam meningkatkan prestasi belajar siswa di SMA Semesta Bilingual Boarding School Semarang. Jurnal Administrasi Pendidikan, 5(4). Retrieved from http://www.jurnal.unsyiah.ac.id/JAP/article/view/9390/7378

Departemen Pendidikan Nasional. (2006). Pemberdayaan komite sekolah. Jakarta: Direktorat Jendral Manajemen Pendidikan Dasar dan Menengah.

Erola, J., Jalonen, S., \& Lehti, H. (2016). Research in social stratification and mobility parental education, class and income over early life course and children's achievement. Research in Social Stratification and Mobility, 44, 33-43. doi: https://doi.org/10.1016/j.rssm.2016.01.003

Ghalili, Z., Etemadi, O., Ahmadi, S. A., Fatehizadeh, M., \& Abedi, M. R. (2012). Marriage readiness criteria among young adults of Isfahan: A qualitative study. Interdisciplinary Journal of Contemporary Research in Business, 4(4), 1076-1083. Retrieved from https://journalarchieves23.webs.com/1076-1083.pdf

Irwansa, A., \& Maf'ul, M. A. (2015). Analisis pelaksanaan tata tertib sekolah pada siswa di SMK Negeri 1 Makassar. Jurnal Tomalebbi, 2(1), 1-13. Retrieved from http://103.76.50.195/tomalebbi/article/view/1670

Kharmina, N. (2011). Hubungan antara tingkat pendidikan orang tua dengan orientasi pola asuh anak usia dini (Unpupblished bachelor's thesis). Universitas Negeri Semarang, Indonesa.

Kusmaedi, N., Husdarta, J. S., \& Hidayat, Y. (2004). Pertumbuhan dan perkembangan sepanjang rentang kehidupan konsep, teori, dan implikasi-pengaruh timbal balik terhadap penjas dan olahraga. Bandung: FPOK UPI.

Lestari, R. M., Hanum, S. H., \& Nopianti, H. (2016). Problema kehidupan berkeluarga pasangan suami istri kawin muda (Studi kasus: Desa Sri Kuncoro Kecamatan Pondok Kelapa, Kabupaten Bengkulu Tengah). Jurnal Sosiologi Nusantara, 2(2), 82-93. doi: https://doi.org/10.33369/jsn.2.2.82-93

Mansur, I. (2005). Pendidikan anak usia dini dalam Islam. Yogyakarta: Pustaka Pelajar. 
Megawati, M., \& Kahar, F. (2017). Pengaruh komunikasi orang tua dengan guru terhadap peningkatan kualitas pembelajaran. Jurnal Office: Jurnal Pemikiran Ilmiah dan Pendidikan Administrasi Perkantoran, 3(1), 33-42. doi: https://doi.org/10.26858/jo.v3i1.3458

Morales-Asencio, J. M, Martin-Santos, F. J., Morilla-Herrera, J. C., Fernández-Gallego, M. C., Celdrán-Mañas, M., Navarro-Moya, F. J., Rodríguez-Salvador, M. M., Muñoz-Ronda, F. J., Gonzalo-Jiménez, E., \& Carrasco, A. M. (2010). Design of a case management model for people with chronic disease (Heart Failure and COPD). Phase I: modeling and identification of the main components of the intervention through their actors: patients and professionals (DELTA-icE-PRO Study). BMC Health Services Research, 10(1), 1-7. doi: https://doi.org/10.1186/1472-6963-10-324

Nurihsan, A. J., \& Sudianto, A. (2005). Manajemen bimbingan dan konseling di SD/MI. Jakarta: Grasindo

Piaget, J., \& Inhelder, B. (2010). Psikologi anak. (M. Jannah, Trans.). Yogyakarta: Pustaka Pelajar.

Purnamasari, I. (2017). Homeschooling dalam potret politik pendidikan: Studi etnografi pada pelaku homeschooling di Yogyakarta. Journal of Nonformal Education, 3(1), 28-39. doi: https://doi.org/10.15294/jne.v3i1.8844

Setyowati, Y. D., Krisnatuti, D., \& Hastuti, D. (2017). Pengaruh kesiapan menjadi orang tua dan pola asuh psikososial terhadap perkembangan sosial anak. Jurnal Ilmu Keluarga \& Konsumen, 10(2), 95-106. doi: https://doi.org/10.24156/jikk.2017.10.2.95

Sick, N., Spaulding, S., \& Park, Y. (2018). Understanding young-parent families: A Profile of parents ages 18 to 24 using the survey of income and program participation. Washington, DC: Urban Institute.

Suardi, S. (2017). Pendidikan keluarga: Basis pendidikan pertama dan utama dalam membina ketahanan moral anak usia dini. Prosiding Seminar Nasional Himpunan Sarjana Ilmu-ilmu Sosial, 2 (February), 171-178. Retrieved from https://ojs.unm.ac.id/PSNHSIS/article/view/2742/1484

Subiyanto, S. (2011). Manajemen strategik pemberdayaan orang tua/wali murid. Edukasi: Jurnal Penelitian dan Artikel Pendidikan, 3(6), 205-211. Retrieved from http://journal.ummgl.ac.id/index.php/edukasi/article/view/593/386

Sugihartono, S. (2015). Psikologi pendidikan. Yogyakarta: UNY Press.

Ulfatin, N. (2015). Metode penelitian kualitatif di bidang pendidikan: Teori dan aplikasinya. Jakarta: Media Nusa Creative.

World Health Organization. (2010). The World Health Organization Quality Of Life (WHOQOL). 